\title{
Study of automatic generation control in two area power system with DFIG-based wind energy conversion
}

\author{
Soumia Kail, Abdelkader Bekri, Abdeldjebar Hazzab \\ Department of Electrical Engineering, CAOSEE laboratory, Tahri Mohammad University, Bechar, Algeria
}

\begin{tabular}{l}
\hline Article Info \\
\hline Article history: \\
Received Dec 20, 2018 \\
Revised Mar 1, 2019 \\
Accepted Apr 22, 2019 \\
\hline Keywords: \\
Area Control Error (ACE) \\
Automatic Generation Control \\
(AGC) \\
Doubly Fed Induction \\
Generator (DFIG) \\
Fuzzy Logic Controller (FLC) \\
PID controller \\
Wind Energy Conversion \\
(WEC) \\
\hline
\end{tabular}

\begin{abstract}
The main objective of Automatic Generation Control (AGC) is to keep the frequency within specified limits through primary and secondary control. In this study, a model of two area thermal non-reheat power system with integration of Doubly Fed Induction Generator (DFIG) based Wind Energy Conversion (WEC) into both areas is presented. A Proportional Integral Derivative (PID) controller and a Fuzzy Logic Controller (FLC) have been applied and compared. The Proposed controllers are used to improve the dynamic response as well as to reduce or eliminate the steady-state error in Area Control Error (ACE). FLC has been offered better and faster performance over the PID controller. The results obtained prove the impact of DFIG-based WEC on AGC and confirm the participation of the DFIG in the frequency system.
\end{abstract}

Copyright (C) 2019 Institute of Advanced Engineering and Science. All rights reserved.

\section{Corresponding Author:}

Soumia Kail,

Department of Electrical Engineering,

COASEE Laboratory, Tahri Mohammad University, Bechar, Algeria

Bechar University, Street Of Independence, BP 417, Bechar, Algeria

Email: kailsoumiya@gmail.com

\section{INTRODUCTION}

The frequency of a system is dependent on active power balance. As frequency is a common factor throughout the system, a change in active power demand at one point is reflected throughout the system by a change in frequency [1].

During normal operations, the system frequency is close to $50 \mathrm{~Hz}$. However, when an event occurs that cause's generation-demand imbalance, the system frequency starts to deviate with the frequency rates, depending on the total system inertia and the amount of unbalanced power [2].

If, for instance, consumption is larger than production, the rotational energy stored in large synchronous machines is utilized to keep the balance between production and consumption and, as a result, the rotational speed of the generators decreases. This results in a decrease of the system frequency. In a power system, there are some units that have frequency-sensitive equipment. These units are called primary control units. The primary control units will increase their generation until the balance between production and consumption is restored and frequency has stabilized. The period of time for this control is $1-30 \mathrm{~s}$ as shown in Figure 1. In order to restore the frequency to its nominal value and release used primary reserves, the secondary control which is known as Automatic Generation Control (AGC) is employed with a time span of $10-15 \mathrm{~min}$. The secondary control thus results in a slower increase or decrease of generation. In some countries, automatic generation control is used; in other countries the secondary control is accomplished manually by request from the system operator [3]. 


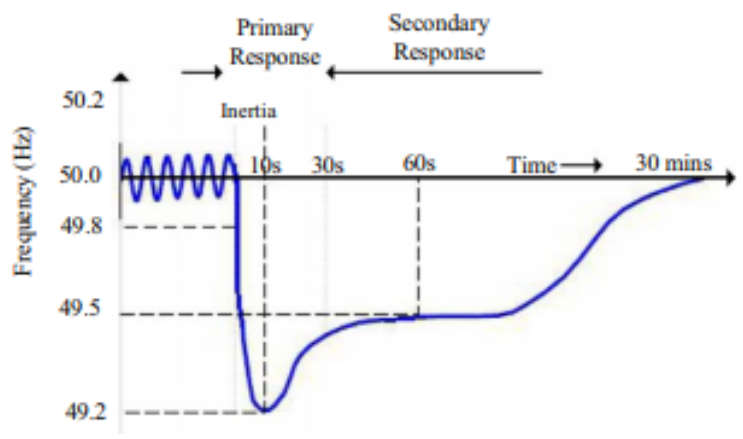

Figure 1. Time frames involved in system frequency response [2]

The dynamic behavior of a power system in the presence of wind power units might be different from that in conventional power plants. The power outputs of such sources are dependent on weather conditions, seasons, and geographic location. When wind power is a part of a power system, additional imbalance is created when the actual wind power deviates from its forecast due to wind velocity variations [4]. Some researchers have carried out research on the possibility of using doubly fed induction based on wind generators to contribute for AGC control. Traditionally wind turbine generation does not participate in frequency regulation services in power systems. With increasing penetration of wind energy, system operators are demanding more and more participation of wind turbines in the ancillary services especially in frequency regulation provisions. As the technology advances, it is possible for wind generators to participate in frequency control services. In the case of DFIGs, the inertia of the turbine is totally decoupled from the system, thus generators are not responding to frequency changes of the power systems. Several methods have been reported in literature on how a variable-speed wind turbine can participate effectively in system frequency regulations [5-8].

To maintain the power system frequency to its nominal value during load change, various types of conventional controllers as proportional $(\mathrm{P})$, proportional-integral (PI), and proportional-integral-derivative (PID) controllers were implemented for AGC control in power systems [9-13]. In [14], the Ziegler-Nichols (ZN) method is used to calculate the optimum values of the PID controller parameters. However, the conventional control techniques may not assure the desired performance due to the complexity and multivariable conditions of the power system. In this present paper, Fuzzy Logic Controller is proposed to analyze the dynamic performance of two area power system with DFIG-based Wind Energy Conversion connected in both area in AGC compared with the PID conventional controller.

This paper is organized in the following order. The second section describes the dynamic model of DFIG with inertial control. The model of two area power system is introduced in the third section. A brief description of PID controller and Fuzzy Logic controller is presented in section four. The fifth section discusses the simulation results. In the end, the conclusion of the paper is presented in section six.

\section{MODELING OF DFIG}

As the penetration of wind energy is increasing into conventional power system, it's desired that DFIG should participate in frequency control. The kinetic energy stored in wind turbine can be extracted with the help of variable-speed generators.

The DFIG based wind turbines are able to produce power with variable mechanical speed and extract the kinetic energy to aid the primary frequency control. The DFIG model used for active power control with dynamic participation of wind turbine is shown in Figure. 2, which has the essence of emulation inertial control. An additional control signal is created to adapt the power set points $\Delta P_{f}^{*}$ as a function of deviation and rate of change of frequency in emulation control of the DFIG. The controllers try to keep the turbine at its optimal speed in order to produce the maximum power. A power set point $\Delta P_{\omega}^{*}$ based on measured speed and measured electrical power is provided by the controller $[5,6]$. The $\Delta P_{N C}$ has two components; $\Delta P_{f}^{*}$ the additional reference point based on frequency changes and $\Delta P_{\omega}^{*}$ which is based on optimum turbine speed as a function of wind speed and as given below:

$$
\begin{aligned}
& \Delta P_{f}^{*}=-K_{d f} \frac{d f}{d t}-K_{p f} \Delta f \\
& \Delta P_{\omega}^{*}=-K_{\omega p}\left(\omega^{*}-\omega\right)+K_{\omega i} \int\left(\omega^{*}-\omega\right) d t
\end{aligned}
$$

Study of automatic generation control in two area power system with DFIG-based wind ... (Soumia Kail) 


$$
\Delta P_{N C}=\Delta P_{f}^{*}+\Delta P_{\omega}^{*}
$$

$K_{d f}$ and $K_{p f}$ are the controller gains for the derivative and proportional controllers respectively. Where $K_{\omega p}$ and $K_{\omega i}$ are constant of PI controller, which provides fast speed recovery and transient speed variation, which helps non-conventional generators to supply the required active power to reduce deviations. The contribution of the DFIG towards system inertia is given by:

$$
\frac{2 H}{f} \frac{d \Delta f}{d t}=\Delta P_{f}-D \Delta f=\Delta P_{g}+\Delta P_{N C}-\Delta P_{t i e 12}-\Delta P_{D}-D \Delta f
$$

A methodology to optimize the controller parameters of doubly fed induction generator modeled for frequency regulation in interconnected two-area wind power integrated thermal power system is proposed in $[15]$.

It has an additional reference power setting that is developed on the change in frequency using a washout filter with time constant $T_{\omega}$, whereas, the reference point $\Delta P_{f}^{*}$, can be derived from the following equation:

$$
\Delta P_{f}^{*}=\frac{1}{R}\left(\Delta X_{2}\right)
$$

Where, $R$ is droop constant and $\Delta X_{2}$ is change in frequency calculated where wind turbine is connected to the grid.

The DFIG responds in accordance with the frequency deviations during load perturbations by using their stored kinetic energy. The proposed controller uses frequency deviation instead of derivative of frequency to provide fast active power injection control.

The injected active power by the wind turbine during disturbances is given as $\Delta P_{N C}$. The injected power by wind turbine is compared with $\Delta P_{N C \text {-ref }}$ for obtaining maximum power output, which is obtained by maintaining reference rotor speed [6].

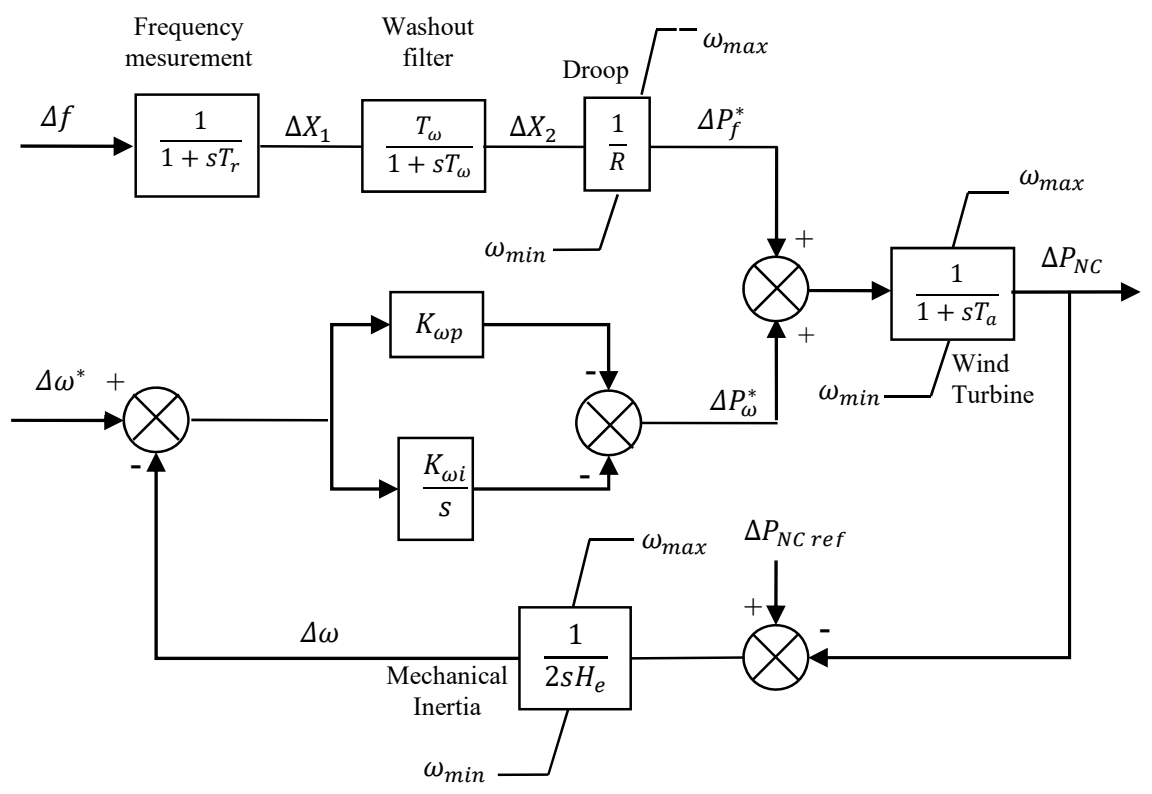

Figure 2. Model of DFIG-based inertial control

The captured mechanical power of wind turbine is given as:

Int J Pow Elec \& Dri Syst Vol. 10, No. 4, Dec 2019 : 2118 - 2125 


$$
P_{\text {mech }}=\left(\frac{\frac{1}{2}\left(\rho A_{r}\right)}{S_{n}} C_{p . o p t}\right) \omega_{s}^{3}
$$

Where

$A_{r}$ is the rotor swept area in $\mathrm{m}^{2}$,

$S_{n}$ is the wind turbine rating in MW,

$\omega_{s}$ is the wind speed,

$C_{p . o p t}$ is the max value of the $C_{p}$ curve at a pitch angle $\beta=0^{\circ}$,

$\rho$ is the air density in $\mathrm{kg} / \mathrm{m}^{3}$.

\section{TWO AREA POWER SYSTEM}

The system consists of two areas with two identical non-reheat turbines is shown in Figure. 3, which are connected to each other through tie-lines. The tie line allows electric power to flow between the areas. Each area has three major components, which are turbine, governor, and generator. DFIG based WEC is integrated in both areas in the presence of the load change.

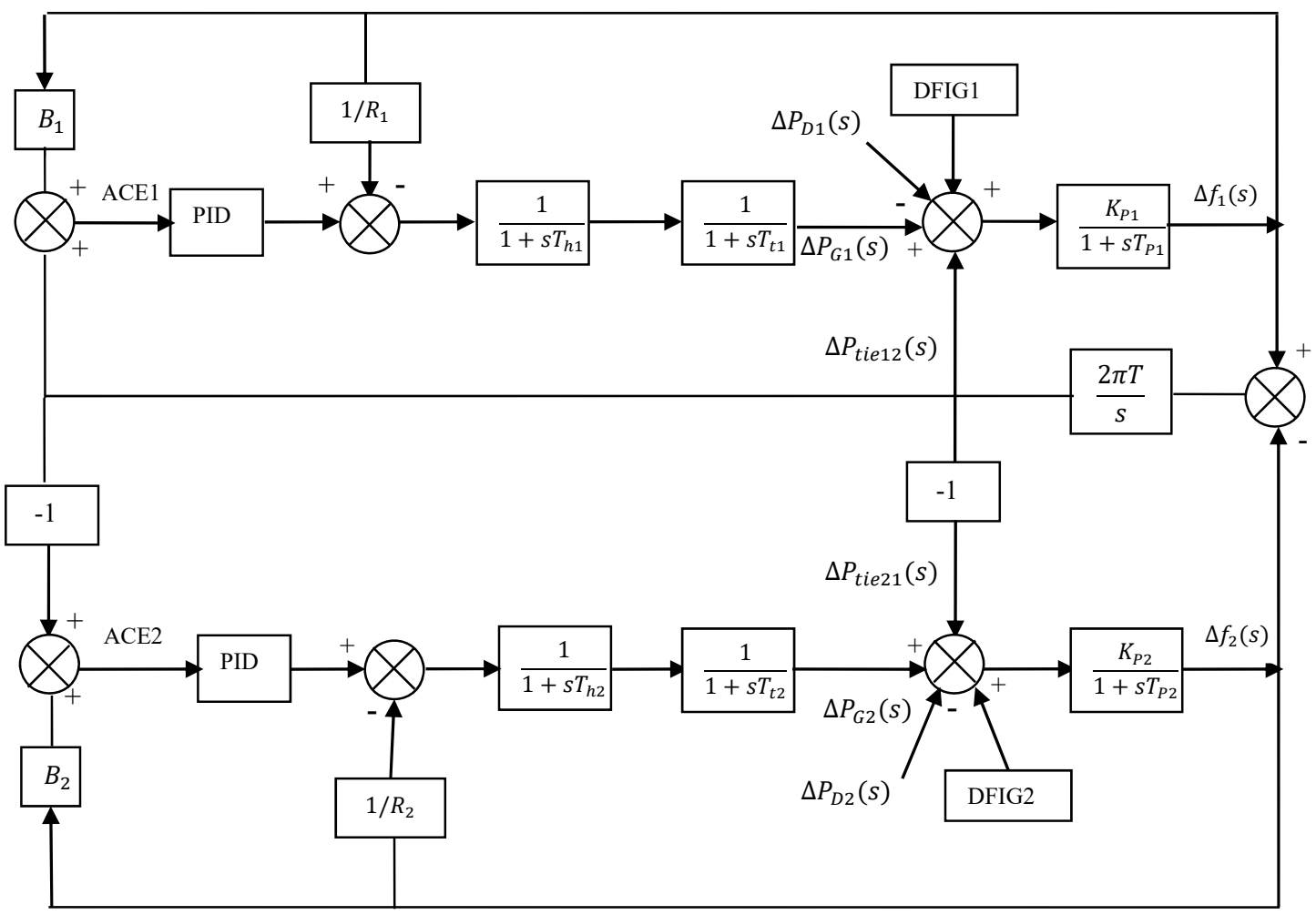

Figure 3. Dynamic Model of two area interconnected power system with DFIG-based WEC connected to both area

\section{THE CONTROLLERS}

In this paper, two controllers are investigated, namely: the PID controller and the fuzzy logic controller.

Proportional Integral Derivative (PID) controllers have been used form last seven decades by various electrical utilities. They play a major role in industrial process control.The PID controllers are used for minimizing the frequency deviations in single or multi area power systems employing AGC. In order to achieve optimal response of the system [16]. PID controller widely used because of simple design and its

Study of automatic generation control in two area power system with DFIG-based wind ... (Soumia Kail) 
robust performance against wide range of operating conditions. The mathematical description of PID as follow:

$$
u(t)=K_{P} e(t)+K_{I} \int_{0}^{t} e(x) \cdot d x+K_{D} \frac{d e(t)}{d t}
$$

Where $e(t)$ is the error value and $u(t)$ is the control variable.

$K_{p}, K_{i}$ and $K_{d}$, all non-negative, denote the coefficients for the proportional, integral, and derivative terms respectively. In this work, the PID parameters have been tuned by Ziegler-Nichols method.

Fuzzy control is based on a logical system called fuzzy logic which is much closer in spirit to human thinking and natural language than classical logical systems [17].

Fuzzy logic is used in almost all fields of science and technology, including solving a wide range of control problems in power system control and operation. There are many possible fuzzy logic controller structures for AGC purposes, some differing significantly from each other by the number and type of inputs and outputs, or less significantly by the number and type of input and output fuzzy sets and their membership functions, or by the type of control rules, inference engine, and defuzzification method. In fact, it is up to the designer to decide which controller structure would be optimal for the AGC problem [4].

$\mathrm{ACE}$ and its derivative are taken as inputs for the Fuzzy logic controller (Figure 4). ACE is proportional to frequency deviation and tie line power deviation. So, ACE needs to be controlled to zero in each area. In this study "Mamdani type" fuzzy inference system is used and the rules of the Fuzzy logic controller are presented in Table.1; which are based on the value of the ACE and the change in the ACE.

Table 1. Fuzzy rules

\begin{tabular}{|c|c|c|c|c|c|c|c|c|}
\hline & & \multicolumn{4}{|c|}{$\triangle \mathrm{ACE}$} & \multirow[b]{2}{*}{ PS } & \multirow[b]{2}{*}{ PM } & \multirow[b]{2}{*}{ PB } \\
\hline & & NB & NM & NS & ZE & & & \\
\hline \multirow{7}{*}{$\mathrm{ACE}$} & NB & NB & NB & NB & NM & NS & NS & $\mathrm{ZE}$ \\
\hline & NM & NB & NM & NM & NM & NS & $\mathrm{ZE}$ & PS \\
\hline & NS & NB & NM & NS & NS & $\mathrm{ZE}$ & PS & PM \\
\hline & $\mathrm{ZE}$ & NB & NM & NS & ZE & PS & PM & PB \\
\hline & PS & NM & NS & $\mathrm{ZE}$ & PS & PS & PM & PB \\
\hline & PM & NS & $\mathrm{ZE}$ & PS & PM & PM & PM & PB \\
\hline & PB & $\mathrm{ZE}$ & PS & PS & PM & PB & PB & PB \\
\hline
\end{tabular}

NB: Negative Big, NM: Negative Medium, NS: Negative Small, ZE: Zero, PB: Positive Big, PM: Positive Medium, PS: Positive Small

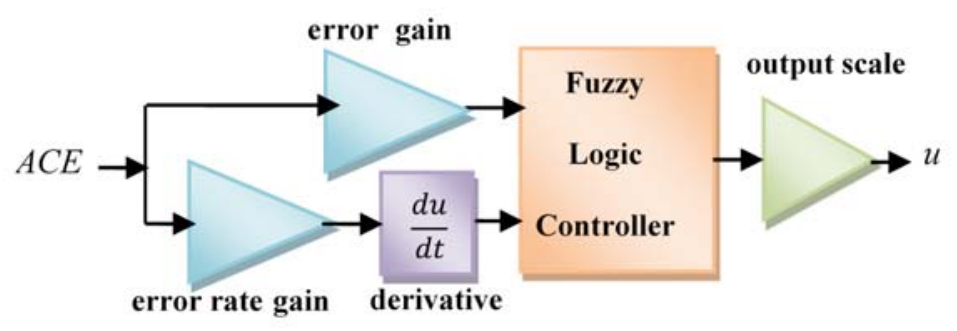

Figure 4. Structure of Proposed Fuzzy Logic Controller

\section{SIMULATION RESULTS}

Two area of non-reheat power plant power system with DFIG based WEC was used to analyze the dynamic behavior when the load increases by 0.02 p.u (i.e $40 \mathrm{MW}$ ) in both areas. Different wind penetration levels have been used to investigate the impact of DFIG on AGC. The presence and the absence of DFIG in the system have been tested to examine its role in the system. The simulation is divided in three cases as follow:

\subsection{Comparison between PID controller and fuzzy logic controller}

Int J Pow Elec \& Dri Syst Vol. 10, No. 4, Dec 2019 : 2118 - 2125 
The performance of PID controller was compared with the intelligent technique Fuzzy Logic Controller (FLC) with step load of 0.02 p.u in both areas. Both controllers are applied to a two area nonreheat power plant. Frequency responses of area 1 and area 2 are shown in Figure 5 and Figure 6 respectively.

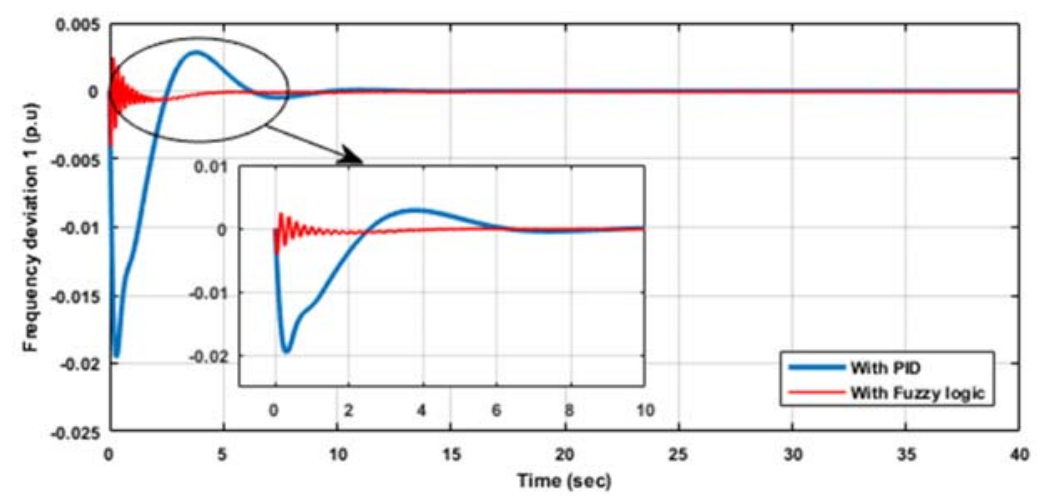

Figure 5. Frequency deviation with $2 \%$ step load change in area 1

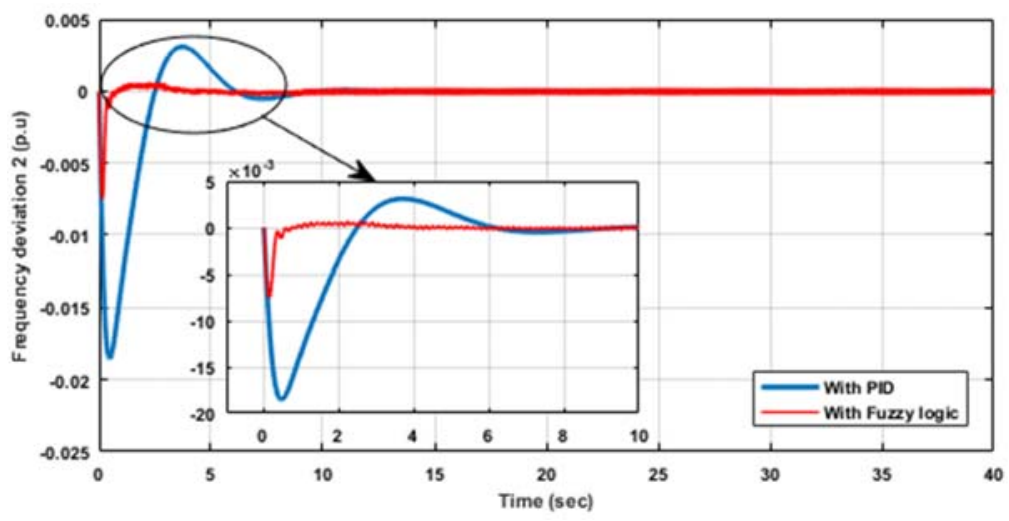

Figure 6. Frequency response with $2 \%$ step load change in area 2

Figure 5 and Figure 6 show that the responses with Fuzzy logic controller are stable with very less overshoot, less settling time and the frequency deviations are minimized. It is found that FLC is better than the conventional controllers in [9-14]. Thus the performance of FLC is faster and better than the PID controller which gives better stability for AGC of a two area power system.

\subsection{The DFIG impact on AGC}

The different wind penetration levels of $5 \%, 10 \%$ and $20 \%$ are used to investigate the influence of wind power on AGC with $2 \%$ step load change in both areas. The wind penetration levels $\left(\alpha_{\mathrm{w}} \%\right)$ is defined as follows:

$$
\alpha_{W}=\frac{\text { Total wind generation }}{\text { Total generation from all sources }} \times 100
$$

$\alpha_{w} \%$ wind penetration means that the existing generator units are reduced by $\alpha_{w} \%$, i.e $\alpha_{w} \%$ reduction in inertia and increase in permanent droop $(R)$ without frequency support.

Figure 7 shows frequency deviation responses of the two area for different wind power penetration, it is observed that the steady-state frequency deviation may increase as the wind power penetration level increases. But a larger penetration may degrade the dynamic performance of the system with increased settling time and higher steady-state errors.

Study of automatic generation control in two area power system with DFIG-based wind ... (Soumia Kail) 


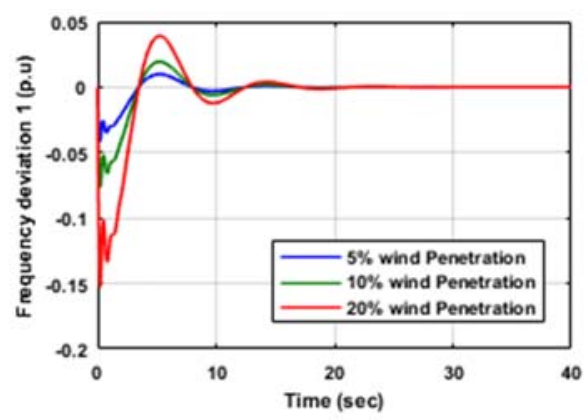

(a)

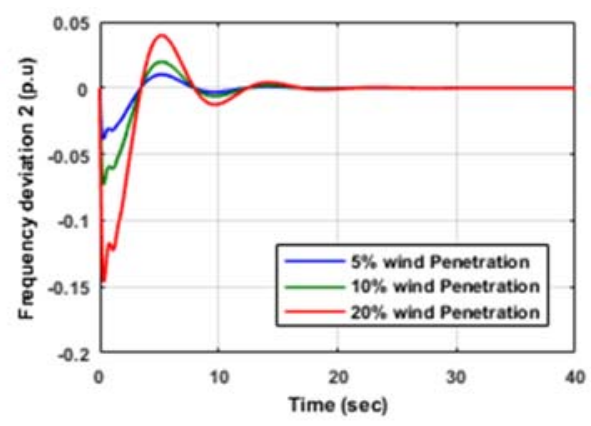

(b)

Figure 7. Frequency response with different levels of wind penetration, (a) in area 1, (b) in area 2

\subsection{With and without DFIG}

The frequency responses of the two areas are presented for the cases where the DFIG is participating in frequency control and not participating in frequency control with step load of $0.02 \mathrm{p} . \mathrm{u}$ in both areas. The two area system has been simulated with PID controller.

Figure 8 and Figure 9 show the comparative response of frequency deviation in area 1 and 2 and tieline power deviation with and without DFIG with $2 \%$ step load change in both areas. It is observed that the frequency response with DFIG is improved by reducing the active power. It is also observed that the settling time is improved.

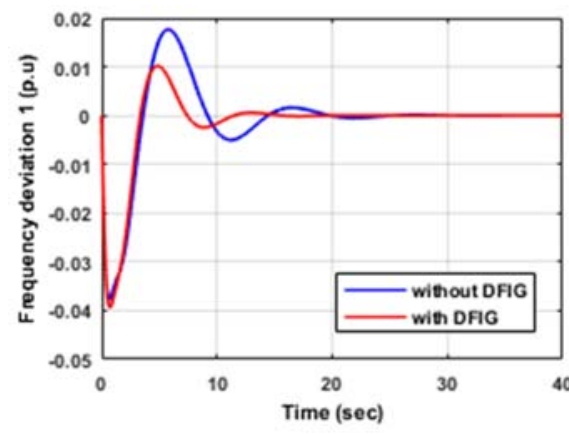

(a)

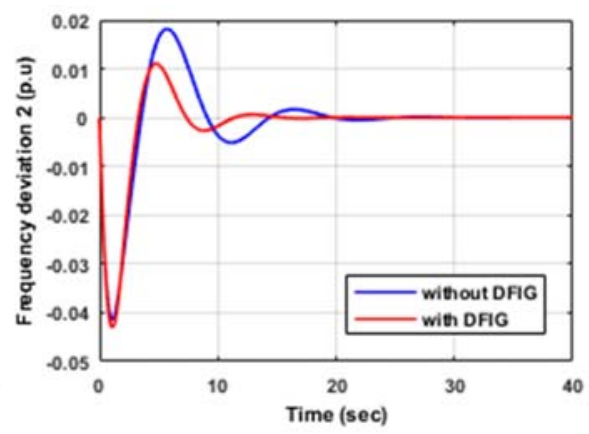

(b)

Figure 8. Frequency response with and without DFIG, (a) in area 1, (b) in area 2

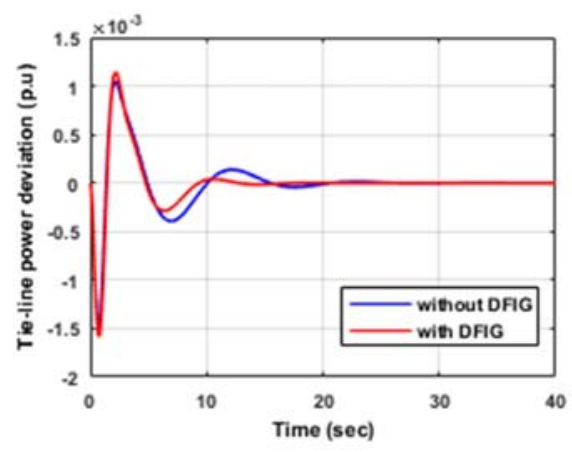

Figure. 9 Tie-line power deviation with 2\% step load change

\section{CONCLUSION}


This paper presents Automatic Generation Control (AGC) in two area power system with two nonreheat thermal power units. Each area is integrated with DFIG-based on Wind Energy Conversion (WEC) with $2 \%$ step change in load in both areas. The Proportional Integral Derivative (PID) and Fuzzy Logic Controller (FLC) have been applied and system performance has been analyzed and compared in terms of frequency response. Both controllers were applied to a two area. The Fuzzy Logic controller offers better and faster performance over the conventional controller. The simulation results show that the fuzzy logic controller reduces the overshoots and the settling time regarding PID controller. The wind penetration impact has been investigated. As the penetration of wind power increases, the frequency deviation increases. The presence of DFIG has improved the dynamic response of frequency compared to without DFIG. Hence, The DFIG based WEC could be utilized to participate and improve the frequency performance.

\section{ACKNOWLEDGEMENTS}

Authors would like to thank the heads of Laboratory of Analysis, Control and Optimization of Electro-Energetic Systems (CAOSEE) in TAHRI Mohammed university of Bechar (Algeria).

\section{REFERENCES}

[1] P. Kundur, "Power System Stability and Control," New York: McGrawHill, 1994.

[2] Dreidy M, Mokhlis H, Mekhilef S, "Inertia response and frequency control techniques for renewable energy sources: A review", Renewable and Sustainable Energy Reviews, vol. 69, pp.144-155, Mar 2017.

[3] Ackermann T, editor, "Wind power in power systems," Chichester, UK: John Wiley, 2005.

[4] Bevrani H, Hiyama T, "Intelligent automatic generation control," CRC press, Apr 2016.

[5] Jalali M, Bhattacharya K, "Frequency regulation and AGC in isolated systems with DFIG-based wind turbines," InPower and Energy Society General Meeting (PES), pp. 1-5, IEEE 2013.

[6] Ibraheem, Niazi KR, Sharma G, "Study on dynamic participation of wind turbines in automatic generation control of power systems," Electric Power Components and Systems, vol. 43(1), pp. 44-55, Jan 2015.

[7] Verma, Yajvender Pal, and Ashwani Kumar, "Dynamic contribution of variable-speed wind energy conversion system in system frequency regulation,"Frontiers in energy, vol. 6(2), pp. 184-192, 2012.

[8] Ahmadi R, Sheikholeslami A, Nabavi Niaki A, Ranjbar A, "Dynamic participation of doubly fed induction generators in multi-control area load frequency control," International Transactions on Electrical Energy Systems, vol. 25(7), pp.1130-1147, 2014.

[9] Avinash, and L. B. Prasad, "Load frequency control of interconnected five-area power system with PID controller," In 2017 International Conference on Information, Communication, Instrumentation and Control (ICICIC), pp. 1-8. IEEE, 2017.

[10] Ankita, Harinder Singh, and Krishan Arora, "Automatic generation control of two equal areas with traditional controllers," International Journal of Power Electronics and Drive Systems (IJPEDS), vol. 7(3), pp. 610-616, 2016.

[11] Azeer SA, Ramjug-Ballgobin R, Hassen SS, "Intelligent controllers for load frequency control of two-area power system," IFAC-PapersOnLine, vol. 50(2), pp. 301-306, Dec 2017.

[12] Kumari R, Avtar MR, "Automatic generation control of multi area power system using PID controller," International Journal of Engineering Trends and Technology (IJETT), vol. 4(5), May 2013.

[13] Thakur GS, Patra A, "Load frequency control in single area with traditional ziegler-nichols pid tuning controller," International Journal of Research in Advent Technology, vol. 2(12), pp. 5-9, Nov 2014.

[14] Jain, Dharmendra, M. K. Bhaskar, Shyam K. Joshi, and Deepak Bohra, "Analysis of load frequency control problem for interconnected power system using PID controller," Int. J. Emerg. Technol. Adv. Eng (IJETAE), vol. 4(11), 2014.

[15] Chaine S, Tripathy M, Satpathy S, "NSGA-II based optimal control scheme of wind thermal power system for improvement of frequency regulation characteristics," Ain Shams Engineering Journal, vol. 6(3), pp. 851-863, Sep 2015.

[16] Meena SK, Chanana S, "Comparative study of load frequency control using PID and FGPI controller," InPower India International Conference (PIICON), 6th IEEE, pp. 1-6, 2014

[17] Arya, Yogendra, Narendra Kumar, and Hitesh Dutt Mathur, "Automatic generation control in multi area interconnected power system by using HVDC links," International Journal of Power Electronics and Drive Systems (IJPEDS), vol. 2(1), pp. 67-75, 2012. 